\title{
Correction to: Entrepreneurial bricolage and online store performance in emerging economies
}

\author{
Xiaoyu $\mathrm{Yu}^{1} \cdot$ Yajie $\mathrm{Li}^{1} \cdot$ Daniel Q. Chen ${ }^{2} \cdot$ Xiaotong Meng $^{1} \cdot$ Xiangming Tao $^{3} \cdot$ Bang Nguyen $^{4}$ \\ Published online: 29 September 2018 \\ (C) Institute of Applied Informatics at University of Leipzig 2018
}

\section{Correction to: Electron Markets}

https://doi.org/10.1007/s12525-018-0302-9

The original version of this paper missed to capture the author, Bang Nguyen, and is now added on this article.

The online version of the original article can be found at https://doi.org/ $10.1007 / \mathrm{s} 12525-018-0302-9$

Yajie Li

roxyli@i.shu.edu.cn

Xiaoyu Yu

yuxiaoyu@vip.126.com

Daniel Q. Chen

d.chen@tcu.edu

Xiaotong Meng

mengxiaotong_jy@163.com

Xiangming Tao

xiangming.tao.2016@live.rhul.ac.uk
Bang Nguyen

bang.london@gmail.com

1 School of Management, Shanghai University, 99 Shangda Road, Shanghai 200444, People's Republic of China

2 Neeley School of Business, Texas Christian University, 2900 Lubbock, Fort Worth, TX 76109, USA

3 School of Management, Royal Holloway, University of London, Highfield Road, London TW20 0EX, UK

4 Department of Entrepreneurship and Relationship Management, University of Southern Denmark,

Universitetsparken 1, DK-6000 Kolding, Denmark 